\title{
Edmund H. Sonnenblick
}

dmund H. Sonnenblick, the Safra Distinguished University Professor of Medicine and chief emeritus of the Division of Cardiology at the Albert Einstein College of Medicine, died on September 22, 2007, of esophageal cancer, at the age of 75 .

After graduating with honors from Wesleyan University and Harvard Medical School, Ed began his residency at New York Presbyterian Hospital. He interrupted his residency to spend two years in the Laboratory of Cardiovascular Physiology at the NIH. At the age of 30, Ed veritably exploded on the cardiovascular firmament with two fundamental discoveries, his two grand slam home runs. In a single-authored paper, Ed described the force-velocity relation of isolated cardiac muscle. He showed for the first time that both the extent and velocity of muscle shortening are determined by the length of the muscle at the onset of contraction (preload), the force that the muscle is called upon to generate (afterload), and the muscle's inotropic (contractile) state. The principles established by Sonnenblick in 1962 are now so deeply ingrained in the minds of investigators and students in cardiovascular physiology that they are simply taken for granted.

Although he had almost single-handedly created what was a new field - myocardial muscle mechanics - Ed still had to complete his clinical training, since his intent was to become a physician-scientist. He returned to New York Presbyterian Hospital for his senior medical residency, during which he hit his second grand slam home run. Using the recently developed technique of quantitative electron microscopy, Ed related the length of the cardiac sarcomere and the position of the thick and thin filaments at the time of their activation to the heart muscle's diastolic tension as well as to the force of contraction. Thereby, he provided the ultrastructural basis of the Starling law of the heart. I vividly recall sitting in the auditorium of the Steel Pier in Atlantic City in 1963 when Ed rose to present this work before the American Society for Clinical Investigation. The audience was rapt because they sensed that something big was in the air. I also recall the awestruck president of the society opening the discussion of Ed's paper (published immediately in the Proceedings of the National Academy of Sciences) by saying with admiration, "If I were born again, I would surely become an electron microscopist."

Ed then returned to the NIH and joined the Cardiology Branch, which I headed at the time. He, John Ross, and I collaborated very closely for four exciting years. First, we extended the framework of myocardial muscle mechanics to the intact dog heart and then to the human heart. In one of our papers, first-authored by Ed, we showed in subjects with radiopaque markers sewn to the left ventricle during operation that even mild exercise shifted the ventricle's force velocity relation and that this shift

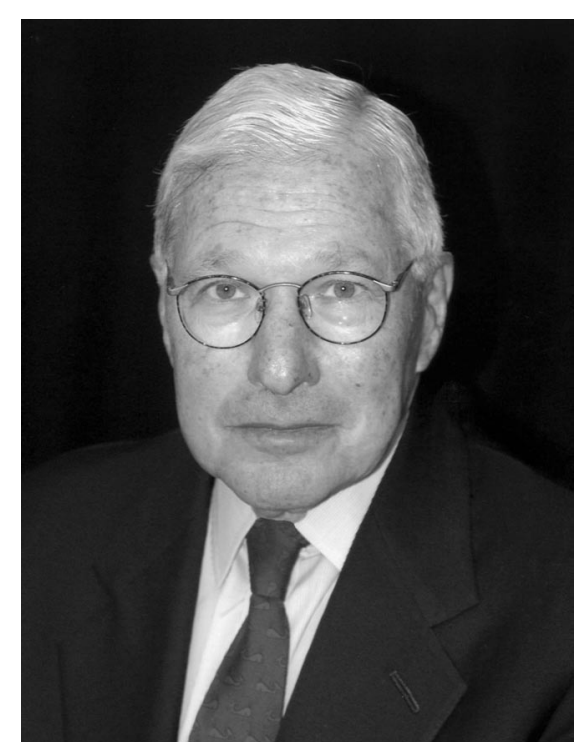

could be abolished by $\beta$-adrenergic blockade, demonstrating for the first time the critical importance of activation of the sympathetic nervous system to the human heart's response to exercise.

The logical next step was to define muscle mechanics of isolated myocardium obtained from cats in which heart failure had been induced. A depression of the force-velocity curve was observed, signifying a depression of intrinsic contractility. Thus, in five short years (1962 to 1967), Ed had established the fundamental muscle mechanics of isolated cat papillary muscle and extended these to the intact dog heart, then to the normal intact human heart, and finally to muscle isolated from the failing heart.

As a consequence of these paradigm-shifting discoveries, Ed Sonnenblick occupies an honored place along with Ernest Starling, Carl Wiggers, and very few others in the pantheon of the greatest cardiovascular physiologists of the twentieth century.

Ed returned to Harvard and the Brigham. Notable among his many discoveries was his description of a functional defect in the sarcoplasmic reticulum of the heart of the hereditary cardiomyopathic hamster, one of the first biochemical defects of the failing heart. Ed then accepted a professorship and the task of creating a modern cardiovascular division at the Albert Einstein College of Medicine. He promptly recruited a cadre of outstanding investigators and clinicians who were attracted by his restless, creative mind. Ed supported the development of one of the country's first integrated molecular cardiology programs. Under his enlightened leadership, the division prospered and rapidly moved into the front ranks of such divisions in the country. Ed's research during this period was both broad and deep, and it was always innovative.

After assuming emeritus status, Ed moved into a totally new area - he collaborated with Piero Anversa and his team on stem cell therapy of the murine heart with heart failure. Weeks before his death, he spoke to me of this work with the same excitement that was present when we first met at the NIH 47 years earlier.

Shortly before his death, he learned that the American Heart Association had awarded him its most prestigious prize: the Research Achievement Award. After Ed's death, Richard Kitsis, who accepted the award for Ed, discovered his handwritten acceptance speech. Ed wrote, "Like a mitral valve, my introduction to cardiology began with an opening snap ... My first paper on the heart as a muscle seemed a small step then but set the stage for a generation of cardiac research. My colleagues have been as much friends as collaborators ... I hope the current generation of researchers have as much fun together and satisfaction as we did. It is the ties with close friends and family that matter the most, and it is the respect of our peers that motivates us.”

\section{Eugene Braunwald}

Department of Medicine, Brigham and Women's Hospital and Harvard Medical School, Boston, Massachusetts, USA. E-mail: ebraunwald@partners.org. 